\title{
Alteridade em movimento no filme Cinema aspirinas e urubus, de Marcelo Gomes
}

\author{
Afonso Manoel da Silva Barbosa \\ Doutorando em Letras pela \\ Universidade Federal da Paraíba. \\ Participa do grupo de pesquisa Ficção \\ audiovisual, Comunicação e Produção \\ de Sentido. \\ E-mail: afonso780@yahoo.com.br
}

\section{Luiz Antonio Mousinho Magalhães}

Doutor em Teoria e História Literária pela Universidade Estadual de

Campinas. Bolsista de produtividade em pesquisa do CNPq e professor associado III da Universidade Federal da Paraíba.

E-mail:Imousinho@yahoo.com.br
Resumo: Pretendemos analisar o longa-metragem Cinema aspirinas e urubus, de Marcelo Gomes, examinando os personagens Johann e Ranulpho, com atenção para suas identidades construídas em diálogo, como gestos de instauração da alteridade. $O$ estudo visa discutir ainda os dados da linguagem cinematográfica utilizados na construção desses embates entre as personalidades do nativo e do estrangeiro, abordando a obra a partir do conceito de dialogismo.

Palavras-chave: Cinema; Alteridade; Dialogismo.

\section{Title: Alterity in motion in Cinema aspirins and vultures, by Marcelo Gomes}

Abstract: We intend to analyze the movie Cinema Aspirins and Vultures (Cinema aspirinas e urubus) by Marcelo Gomes, examining the characters Johann and Ranulpho, focusing on their identities built in dialogue, as gestures of establishment of alterity. Also, this study aims to discuss the data of cinematographic language used in the construction of these conflicts between the personalities of the native and foreign characters, dealing with the work from the concept of dialogism.

Keywords: Cinema; Alterity; Dialogism. 
Este artigo pretende examinar dados do longa-metragem Cinema aspirinas $e$ urubus, de Marcelo Gomes, abordando a obra a partir da observação da construção dos personagens Johann (Peter Ketnath) e Ranulpho (João Miguel), com atenção para suas identidades construídas em diálogo, como gestos de instauração da alteridade. $O$ trabalho se propõe ainda a analisar a construção dos personagens sob a ótica do dialogismo bakhtiniano no âmbito subjetivo e intersubjetivo, assim como a própria obra enquanto produção artística que se relaciona com outros campos discursivos.

O filme narra a história de Johann, um alemão que, para fugir da 2a Guerra Mundial, veio ao Brasil como vendedor itinerante de aspirinas. Dirigindo um caminhão de sua empresa em meio às veredas do sertão nordestino, ele acaba oferecendo carona a diferentes tipos de pessoas. Uma delas é Ranulpho, um homem ambicioso que pretende ir ao Rio de Janeiro à procura de outras oportunidades de vida. Ele é contratado por Johann enquanto assistente para ajudá-lo na exibição de curtas-metragens que funcionam como propaganda para a venda das pílulas.

$\mathrm{Na}$ representação do sertão nordestino proposta pelo filme, as cores possuem predominância sépia e amarronzada, desde o vestuário à escolha dos cenários naturais, trabalhando na construção de um ambiente quente e seco. A caracterização reforça a dificuldade que o nativo tem para lidar com essas condições e aprofunda essa agrura para Johann enquanto estrangeiro não habituado ao ecossistema.

O cinema, como uma arte da representação, "gera produções simbólicas que exprimem mais ou menos diretamente, mais ou menos explicitamente, mais ou menos conscientemente, um (ou vários) ponto(s) de vista sobre o mundo real" (VANOYE; GOLIOT-LÉTÉ, 1994, p. 61). Lidamos com a forma que Johann e Ranulpho enxergam o mundo e a complementariedade que essas visões acaba alcançando no road movie. Para o nosso estudo, destacamos que "o filme é, portanto, o ponto de partida e de chegada da análise" (Ibid., p. 15). O estudo da construção de uma obra como um longa-metragem deve ressaltar os "elementos sociais que formam a sua matéria, as circunstâncias que influíram na sua elaboração, ou para a sua função na sociedade" (CANDIDO, 1980, p. 11-12). Destacamos, entretanto, que esses dados precisam ser "considerados segundo a função que exercem na economia interna da obra" (Loc. cit.).

No sentido de amplificar a discussão acerca da alteridade, Charles Taylor é preciso quando destaca que "a verdadeira compreensão nas relações humanas exige a paciente identificação e desconstrução das facetas de nossas suposições implícitas que distorcem a realidade do 'outro'" (TAYLOR, 2002, p. 14-15). Com isso, "o momento crucial ocorre quando as diferenças do 'outro' podem ser percebidas não como erros ou defeitos ou ainda como produto de uma versão menor, subdesenvolvida, do que somos, mas como um desafio colocado por uma alternativa humana viável" (Loc. cit.).

Quando trazemos esse debate para o filme de Marcelo Gomes, deparamos com uma construção narrativa que perpassa essas questões. Elas não estão fincadas apenas na aparente ambivalência entre seus protagonistas, mas também engloba a estrutura arquitetada para nos mostrar além dos conflitos entre o nativo e o estrangeiro. Entre outros motivos, os embates se dão no âmbito interno de cada personagem - porque o nativo quer ser estrangeiro assim como o estrangeiro quer ser nativo - ambos numa busca pelo autoexílio, pela redenção poeticamente materializada em forma de travessia.

No entanto, de maneira mais clara, esse choque se dá ainda no âmbito cultural mais evidente entre Ranulpho e Johann. Eles têm a estrada, com sua simbologia cíclica enquanto ambiente catalisador de suas percepções sobre o outro, para 
desencadear um processo de permuta de sentidos. De um lado, o alemão que queria fugir da Guerra; de outro, o retirante que busca melhores condições de vida. Um quer sair, o outro quer ficar: ambos, aos poucos, se reconhecendo simbioticamente num processo que é gerado de um entendimento do outro a partir de uma "compreensão modificada de si mesmo, uma mudança de identidade que [altera] nossos objetivos e nossos valores" (Loc. cit.).

\section{Recursos metafóricos e cinematográficos no sertão nordestino}

Cinema aspirinas e urubus se constitui de uma teia de sutilezas onde é possível observar que as metáforas apresentam-se num "movimento da ambiguidade, e da ausência presentificada" (NUNES, 1993, p. 61). O próprio título do filme que, além de corroborar com a peculiaridade metalinguística da obra, pode também ser compreendido como uma maneira de reforçar o pressuposto comercial da franquia das pílulas, já que não há vírgula entre as palavras "cinema" e "aspirinas".

Podemos examinar esse dado nos detendo a essa construção sem vírgulas e refletindo acerca do arrebatamento que as exibições das propagandas a céu aberto proporcionavam ao público. Não só o cinema pode adquirir um viés ácido acetilsalicílico, mas a arte, em suas diversas manifestações, é capaz de entorpecer, anestesiar. Pode servir eminentemente ao entretenimento ou instigar a criticidade. Pode ainda possuir essas duas facetas numa só obra. E tudo isso está ainda sujeito ao complexo espectro de reação de cada espectador. No entanto, o filme procura representar esse primeiro contato dos sertanejos com as projeções de forma a evidenciar que eles se interessavam mais pela exibição do que pelo remédio. Ou melhor, mais pelo remédio por conta da exibição.

Quando partimos para uma leitura do título escandindo-o como um verso poético, constatamos uma construção de nove sílabas com forte aliteração com o som do "s". O nome do filme, povoado com as cinco vogais, apresenta duas paroxítonas e uma oxítona que se unem em divisões e subdivisões estrategicamente interpoladas:

$\mathrm{Ci} / \mathrm{ne} / \mathrm{ma}$ as / pi / ri / nas / e u / ru / bus.

Ou:

$$
\mathrm{Ci} / \mathrm{ne} / \mathrm{X} / \mathrm{pi} / \mathrm{ri} / \mathrm{X} / \mathrm{eu} / \mathrm{ru} / \mathrm{X}
$$

Esse construto dá força à última - e única oxítona - palavra do título, mostrando ainda depois de cada duas sílabas uma terceira com a presença da letra "s". Essa presença intercalada parece realçar certo dado cíclico de idas e vindas que o próprio filme reafirma em sua narrativa.

É possível ainda assinalar mais detidamente que o uso do título nessa estrutura nos apresenta um dado interpretativo quanto ao poderio propagandístico e logístico da indústria farmacêutica já na época em que a história se passa diegeticamente. Dentre várias possibilidades multifacetadas de leituras e de proliferação de sentidos, o termo "urubus", em relação ao mercenarismo farmacêutico, pode ser compreendido a partir da peculiaridade dessas aves de rapina que sobrevoam carcaças e se alimentam do resto de outros animais.

O uso da handcamera concede maior urgência no efeito produzido por algumas cenas. O recurso ajuda a intensificar uma sensação de certo desconforto por parte dos personagens que estão, com frequência, acomodando-se para o descanso no chão ou no caminhão e estão sempre chegando e partindo de algum lugar.

Esse artifício também explora de maneira eficaz os silêncios na convivência entre Johann e Ranulpho, sugerindo, a partir dos não ditos, sentimentos de rivalidade, 
desaprovação e ciúmes, como na sequência em que eles dão carona à Jovelina. As conversas na boleia do caminhão apresentam-se, por vezes, em cenas com poucos planos ou em cenas que, quando fracionadas em vários planos, não se utilizam do clássico esquema campo/contracampo para captar as reações dos personagens frente às declarações do outro.

A fauna presente no habitat sertanejo nordestino é utilizada no longa-metragem de forma a dar referencialidade ao lugar, mas possui ainda um elo com o poético, gerando efeitos de sentido a partir da relação estabelecida entre ela e os personagens. Apesar de ter sido picado por uma cobra, num evento muito doloroso e com risco de morte, Johann evita matar uma cascavel que lhe arma um bote quando ele está no mato, tentando se livrar de seus documentos para não participar da Guerra.

O gesto do personagem intensifica sua postura "antibelicista", sobretudo quando pensamos nas atribulações que ele havia passado, como a prostração por conta do envenenamento. No entanto, Johann parece reconhecer que, com sua identidade em transmutação (jogando a "antiga" fora), ele agora coexiste num ambiente onde outros seres já habitavam. A adaptação do personagem comporta certa dose de uma visão holística e faz parte do crescimento dele no filme, especialmente, nesse contato com elementos diferentes daqueles com os quais ele estava habituado a conviver a partir da sua antiga identidade.

Podemos observar ainda a questão relacionada ao uso diegético dos urubus em cenas mais próximas ao final do filme, em ambientações que destacam as agruras de uma terra seca e com poucas perspectivas. Por um lado, temos a interpretação do próprio diretor da obra, assinalando que, "naquele momento do filme, o urubu representa as mazelas que pairam sobre as nossas vidas, sejam das pessoas que estão indo de trem pra Amazônia ou de trem para o campo de concentração" (OMELETE, 2005).

Por outro lado, também podemos inferir que as aves revelam e colaboram com o patamar cíclico do filme em relação ao trânsito, ao fato de se estar em movimento contínuo. Isso pode ser percebido seja com Johann que parte de trem para a Amazônia ou com Ranulpho que parte, de caminhão, para o Rio de Janeiro. É possível ainda compreender que os urubus representam certo status de sobrevivência em determinados ambientes hostis, alimentando-se dos restos, e cujo elemento simbólico resvala na miserabilidade, seja ela na indústria da seca nordestina ou no Velho Mundo, onde "as bombas caem do céu". No entanto, apesar das dificuldades, aqueles pássaros também possuem o mecanismo e a força necessária para partir sempre que preciso. Como característica ecológica, os urubus possuem ainda uma importante função no ecossistema, contribuindo sobremaneira para a retirada de carcaças de outros animais em decomposição do meio ambiente. Dessa forma, pensando a construção da obra, é possível reforçar a peculiaridade dessa ave de rapina em relação à vida e à morte no contexto do sertão nordestino e da Segunda Guerra Mundial.

Sobretudo no início e no final do longa-metragem, a fotografia se desdobra numa estética que nos remete ao filme Vidas secas, de Nelson Pereira dos Santos, cujo efeito de luz saturada intensifica a percepção do ambiente quente e seco. Observamos esse procedimento à luz do dialogismo bakhtiniano, no qual há a compreensão de que essas relações intertextuais se desenvolvem a partir da ideia de que o texto é composto por "um 'tecido de vozes', ou de muitos textos ou discursos, que se entrecruzam, se completam" (BARROS, 1997, p. 34).

Além disso, esse recurso de saturação nos dá a impressão de que o fade in do começo abre essa "cortina" para o filme se desdobrar e o fade out, na outra ponta da obra, fecha essa mesma "cortina", encerrando o longa-metragem. Naquele primeiro momento, com Johann dirigindo o caminhão e, no segundo, Ranulpho 
${ }^{1}$ BABO, Lamartine. Serra da Boa Esperança. Disponível em: <http://www. vagalume.com.br/lamartine-babo/serrada-boa-esperanca.html>. Acesso em: 11 ago. 2015.

\footnotetext{
${ }^{2}$ Temos a noção, no entanto, de que a obra hiperboliza essa característica avassaladora do cinema na fala de Johann e que não se trata de uma proposta do próprio filme debater essa questão pragmaticamente. Sabemos que a discussão em torno da recepção cinematográfica, em sua visão mais radicalizada e apocalíptica feita por estudiosos da Escola de Frankfurt, já foi desmistificada por inúmeros autores.
} Deixamos aqui apenas o registro, a título de informação, das considerações de Martín-Barbero em forma de sugestão bibliográfica a respeito do tema no livro Dos meios às mediações: comunicação, cultura e hegemonia, mais precisamente o capítulo Indústria cultural: capitalismo e legitimação. fazendo o mesmo; o que configura o aporte cíclico do filme, ou seja, o estar em trânsito: a trajetória sendo mais importante que a chegada.

A trilha sonora também cumpre um papel semelhante nesse sistema rotatório e itinerante. Além do som de uma sanfoneira que se apresenta num prostíbulo em Triunfo, o registro musical do filme possui um comprometimento estético em larga escala atrelado à programação do rádio do caminhão, que se divide entre boletins geopolíticos e canções da época. A música Serra da Boa Esperança ${ }^{1}$, de Lamartine Babo, na gravação de Francisco Alves, destaca-se por acompanhar a estrutura deflagrada pelo fade in e o fade out, como assinalamos anteriormente. Os versos "no coração de quem vai/No coração de quem vem [...] Parto levando saudades/ Saudade deixando [...] Ó, minha serra, eis a hora do adeus, vou-me embora" (BABO, 1937) caracterizam de forma ainda mais incisiva o tom andarilho de um começo, meio e fim em estágio permanente de rotação.

\section{Metalinguagem e alteridade: o espelho confrontado}

O estatuto metalinguístico da obra vai além da referência dada no título do filme de Marcelo Gomes. Ela se dá, evidentemente, pelo uso em cena do projetor e dos fotogramas, mas investe além da utilização mecânica do equipamento. Devemos atentar para a forma como esses recursos são ressignificados. Um dos artifícios empregados para retratar o encantamento com a projeção cinematográfica se dá pela curiosidade de Ranulpho e ato simbólico de interceptar as propagandas de aspirinas, fazendo-as serem exibidas na palma de sua mão.

Outro artifício que complementa essa conotação autorreflexiva é a veiculação da palavra "fim", em tela cheia, ainda no meio do filme. Funcionando como "uma amputação de elementos discursivos suscetíveis de serem recuperados pelo contexto" (REIS; LOPES, 1988, p. 243), a elipse serve para dinamizar o tempo na obra, ao omitir a exibição novamente da propaganda das aspirinas, mas dando a entender que ela foi realizada.

A propaganda das aspirinas é trabalhada no longa-metragem a partir do uso de elementos cinematográficos como estratégia de convencimento. No escuro natural da noite sertaneja, uma sala de cinema é improvisada ao ar livre, em um gesto que impressiona os cidadãos interioranos, impelindo-os em direção ao consumo do produto, mesmo que o interesse de alguns ali seja maior pelo que o projetor exibe. "De fato, tão intenso é o fascínio que esta arte exerce sobre as multidões que os elementos e processos de seu consumo não estão longe daqueles que engendram e presidem o fenômeno do mito" (BRITO, 1995, p. 223).

A consciência de Johann sobre o poderio dessa ferramenta fica evidente nas palavras do próprio personagem quando ele está negociando a venda do seu equipamento de trabalho para um "empresário" em Triunfo: "Os filmes são muito bem feitos. Eles impressionam todo mundo. Uma pessoa que nunca ter (sic) dor de cabeça, vai começar a ter só pra tomar remédio"2.

Quando pensamos em alteridade, nos voltamos para os estudos de Robert Stam sobre o pensador russo Mikhail Bakhtin, sobretudo por compreendermos que "mais do que simplesmente 'tolerar' a diferença, a abordagem bakhtiniana respeita-a e até a aplaude" (STAM, 2000, p. 14). Nesse sentido, a relação de Johann e Ranulpho está imersa nessa prerrogativa e a diferença no tipo de discurso manifestado vai produzir novas formas de se observar o mundo por ambos os personagens.

Vale ressaltar ainda que Bakhtin "mostra que, ao [depararmos] com a subjetividade alheia, adquirimos a certeza de nossa própria interioridade e da parcialidade irredutível de nossa própria experiência" (COSTA, 2002, p. 11). 0 filme demonstra esse contraponto na forma como Johann e Ranulpho lidam com 
suas diferenças no percurso que realizam. A inserção de outros personagens que também pegam carona no caminhão ou que vão assistir aos comerciais da aspirina reforça esse dado, pois a presença deles acaba gerando reações diferentes por parte dos protagonistas.

Nesse contexto, a forma acolhedora com a qual Johann trata as pessoas contrasta com a postura antipática que Ranulpho se relaciona com boa parte daqueles com quem mantém contato, apesar de ele ser o nativo e aquele o estrangeiro. As discrepâncias ajudam a formatar a ideia de que "ser significa comunicar-se dialogicamente. Quando termina o diálogo, tudo termina" (BAKHTIN apud STAM, 2000, p. 72). O percurso abre espaço para o aprendizado mútuo, além de colocar em evidência questões de alteridade e identidade.

Podemos aqui relacionar o conceito de alteridade ao de antropofagia. Para isso, assinalamos as considerações de Lévi-Strauss a respeito de alguns tipos de práticas antropofágicas quando ele aponta que elas podem caracterizar-se a partir "de uma causa mística, mágica ou religiosa: assim, a ingestão de uma parcela do corpo de um ascendente ou de um fragmento de um cadáver inimigo pode permitir a incorporação das suas virtudes ou ainda a neutralização do seu poder" (LÉVI-STRAUSS, [19--], p. 485).

Já a alteridade, quando observada sob um dos vieses bakhtinianos, nos é apresentada de forma que:

Na existência interior do outro, tal como é vivida por mim (vivida de modo ativo, na categoria alteridade), o que, de um lado, pertence à existência e, do outro lado, ao dever ser, não se situa numa relação conflituosa de hostilidade, mas se constitui num conjunto de fatos que entram em fusão orgânica num único e mesmo plano dos valores. (BAKHTIN, 1997, p. 134).

Dadas as acepções, é possível correlacioná-las, em relação aos personagens, a um deslocamento do que representaria ameaça e migra rumo ao compartilhamento de vivências e saberes, fazendo com que, mutuamente, Ranulpho e Johann se tornem mais fortes para o futuro que o final aberto do filme aponta. Esse conflito gera diálogo - para falarmos uma vez mais com Bakhtin - e, em Cinema aspirinas e urubus, muitas vezes está no espaço reduzido da boleia do caminhão para produzir sentido em enquadramentos que metaforizam efetivamente antropofagia e alteridade.

Dessa forma, somando-se os dois conceitos, observamos particularidades que se aglutinam e que nos ajudam a compreender a relação estabelecida entre os personagens do filme. É importante frisar que esse é um dado peculiar em filmes de estrada, em que o acirramento, a tensão e, muitas vezes com efeito distensivo,

${ }^{3}$ Ou seja, apresentam-se como fios condutores de trechos importantes da trama. Segundo Carlos Ceia, o recurso pode ser utilizado "para fazer referência a todos aqueles motivos recorrentes que, no seio de uma narrativa, se encontram intimamente associados a determinadas personagens, objetos, situações ou conceitos abstratos" (CEIA, 2015). o aprendizado e as relações de amizade funcionam como leitmotiv ${ }^{3}$ na construção narrativa.

Northrop Frye, ao dissertar a respeito da importância do elemento lúdico na arte, assinala que "brincar com o sacrifício humano parece constituir um tema importante da comédia irônica" (1973, p.51). O filme não possui esse viés interpretativo enquanto dado permanente, mas podemos dizer que a utilização dessa proposta pode ser constatada em sequências como aquela em os personagens, já embriagados no final da noite, forjam um campo de batalha e simulam um combate bélico.

Diegeticamente, a cena se passa no dia em que Johann é notificado sobre o decreto presidencial que declara guerra à Alemanha, enfatizando que o vendedor de aspirinas precisa deixar o país e partir de volta à sua terra natal ou ir para um campo de concentração no interior de São Paulo. Embriagados, Johann 
e Ranulpho, que estariam em lados antagônicos por seus respectivos países, compõem ali no sertão nordestino um simulacro quase infantil da Guerra, num movimento lúdico e catártico.

A construção do processo de identificação entre os personagens é fundamentada na narrativa de modo que as diferenças não sejam anuladas, sem inferiorização do outro e assim representando poeticamente o conceito de alteridade. De certa forma, as diferenças são evidenciadas e celebradas, numa representação em que os choques são constantes e servem de motor para produzir sentido dentro do filme.

O acúmulo de conhecimento e o repertório de cada um deles se transformam em dispositivos de troca a partir de "uma pluralidade de vozes que não se fundem em uma consciência, mas que, em vez disso, existem em registros diferentes, gerando um dinamismo dialógico entre elas próprias" (STAM, 2000, p. 96). De um lado, temos Johann ensinando o manuseio dos fotogramas e do projetor cinematográfico, além, claro, das aulas de direção. De outro, temos Ranulpho como uma espécie de tradutor, mediando a compreensão das palavras e do ecossistema, sendo o elo mais preciso entre o alemão e a terra estrangeira. Essa reciprocidade talvez tenha diminuído certo desconforto de Johann e sua sensação de inadequação e talvez tenha ajudado a Ranulpho a sentir mais empatia em relação a seus conterrâneos, além de lhe abrir possibilidades mais venturosas.

O final do filme não nos dá respostas efetivas sobre a sorte dos dois personagens, deixando, de certa forma, a costura ser finalizada pelo espectador, numa perspectiva "fora dos limites do quadro" (XAVIER, 2008, p. 20). Cinema aspirinas $e$ urubus aposta na travessia geográfica e também subjetiva, numa narrativa de viagem na qual o percurso é mais importante que o destino e em que os personagens principais deixaram marcas indeléveis um no outro.

\section{Referências Bibliográficas}

BABO, L. Serra da Boa Esperança, composição de 1937. Disponível em: <http:// www.vagalume.com.br/lamartine-babo/serra-da-boa-esperanca.html>. Acesso em: 11 ago. 2015.

BAKHTIN, M. Estética da criação verbal. Tradução de Maria Ermantina Galvão G. Pereira. São Paulo: Martins Fontes, 1997.

BARROS, D. L. P. Contribuições de Bakhtin às teorias do discurso. In: BRAIT, B. (Org.) Bakhtin, dialogismo e construção de sentido. Campinas: Editora da UNICAMP, 1997.

BRITO, J. B. de. Imagens amadas: ensaios de crítica e teoria do cinema. São Paulo: Ateliê Editorial, 1995.

CANDIDO, A. Literatura e Sociedade: estudos de teoria e história literária. São Paulo: Nacional, 1980.

CEIA, C. E-Dicionário de termos literários. Disponível em: <http://www.edtl. com.pt/index.php?option=com_mtree\&task=viewlink\&link_id=895\&Itemid=2>. Acesso em: 11 ago. 2015.

COSTA, C. Fiç̧ão, comunicação e mídias. São Paulo: Editora Senac, 2002.

FRYE, N. Anatomia da crítica. Tradução de Péricles Eugênio da Silva Ramos. São Paulo: Cultrix, 1973. 
LÉVI-STRAUSS, C. Tristes Trópicos. Tradução de Jorge Constante. Lisboa: Portugália Editora; São Paulo: Martins Fontes, [19--].

MARTíN-BARBERO, J. Dos meios às mediações: comunicação, cultura e hegemonia. Prefácio de Néstor García Canclini. Tradução de Ronald Polito e Sérgio Alcides. 6. ed. Rio de Janeiro: UFRJ, 2009.

NUNES, P. Cinema e poética. 1. ed. Maceió: Trilha editorial, Sergasa, 1993.

OMELETE. Omelete entrevista: O diretor de Cinema, aspirinas e urubus. Disponível em: <http://omelete.uol.com.br/cinema/omelete-entrevista-o-diretor-decinema-aspirinas-e-urubus/\#.U1gsSPIdU2g>. Acesso em: 11 ago. 2015.

REIS, C.; LOPES, A. C. Dicionário de teoria da narrativa. São Paulo: Ática, 1988.

STAM, R. Bakhtin - da teoria literária à cultura de massa. São Paulo: Ática, 2000.

TAYLOR, C. 2002. A distorção objetiva das culturas. Tradução de Luiz Roberto Mendes Gonçalves. Folha de São Paulo, São Paulo, p. 14-15, 11 ago. 2002. Disponível em: <www1.folha.uol.com.br/fsp/mais/fs1108200209.htm>. Acesso em: 11 ago. 2015.

VANOYE, F.; GOLIOT-LÉTÉ, A. Ensaio sobre a análise filmica. Tradução de Marina Appenzeller. Campinas: Papirus, 1994.

VIDAS Secas. Direção: Nelson Pereira dos Santos. Produção: Herbert Richers; Luiz Carlos Barreto; Danilo Trelles. Rio de Janeiro: Luiz Carlos Barreto Produções Cinematográficas, 1963. (103 min.). son., color.

XAVIER, I. O discurso cinematográfico: a opacidade e a transparência. São Paulo: Paz e Terra, 2008. 